\title{
LETTER
}

\section{Enzymatic Models Hydrolyzing Carbohydrates}

\author{
Yasukazu OhKatsu, Takashi Sugino, Kenji Hamada, and Yasushi Watanabe \\ Department of Industrial Chemistry, Faculty of Engineering, Kogakuin Univ. \\ (1-24-2, Nishishinjuku, Shinjuku-ku, Tokyo, T163)
}

Carbon dioxide, providing the problem of warming the earth, is one of substrates of which release should be controlled into the atmosphere, or removal or recovery should be performed from circumstances. Photosynthesis fixed the carbon dioxide utilizing solar energy to produce hexoses, especially glucose, which enter synthetic reactions catalyzed by syntheses to form starch or amylose for storage of nutrients and cellulose or chitin as structural components. The production of such carbohydrates is said to amount to $1 \times$ $10^{11} \mathrm{t} / \mathrm{y}$ of cellulose or $1 \times 10^{9} \sim 1 \times 10^{11} \mathrm{t} / \mathrm{y}$ of chitin. The massive carbohydrates, however, are not utilized effectively, though they may practically be concerned with problems of resources, foods, and so on.

On the standpoint of such circumstance, one of recent trends dealing with carbohydrates is hydrolysis which is conducted using enzymes or mineral acids ; the enzyme is not available easily and is expensive. In the case of the use of acid, cellulose and chitin, in particular, needs a concentrated strong acid such as hydrochloric or sulfuric acid and a higher reaction temperature for hydrolysis. The procedure causes troubles of etching a reaction vessel, accompanying, in some cases, secondary reactions such as decompositions of hexoses produced.

The authors have synthesized many kinds of glycolipids ${ }^{1)}$ which can from micelles or vesicles

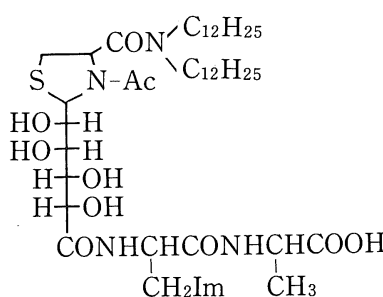

(A)

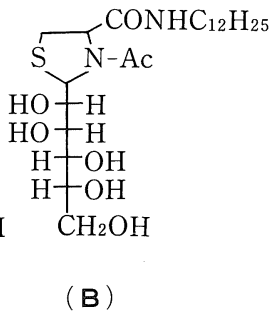

without aid of any surfactant, and they are applied as catalyst to stereo- and substrate-recognizing hydrolyses of $\mathrm{D}, \mathrm{L}$-substrates and amino acid esters respectively. It has been reported also that the combination of glycolipids (A) and (B) in a mole ratio of $1: 1$ recognizes $D, L$-phenylalaninate in a ratio of $103: 1^{2)}$, and also that the glycolipid (C) especially hydrolyses amino acid esters in a similar recognition manner to chymotrypsin ${ }^{3)}$. These facts may interest us in a few aspects that simple glycolipids function as

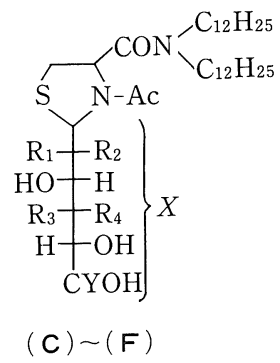
$X$
Y
derived from
(C) mannose $\mathrm{H}_{2}$
(D) galactose $\mathrm{H}_{2}$
(E) glucose $\quad \mathrm{H}_{2}$
( F ) mannose
$\mathrm{O}$

catalyst mimicking a hydrolase, and that such function of suger moiety seems to have a relation to the concept that sugar chains on a cell surface recognize extracellular substrates.

This paper reports that glycolipids such as (C) are enzymatic models for hydrolysis of carbohydrates, also exhibiting the recognition of $\alpha-1$, 4 -and $\beta-1,4$-bonds. This is the first report describing hydrolase models of carbohydrates as long as we know.

Glycolipids used in this study are (C), (D), $(E)$, and (F), which are synthesized from respective corresponding monosaccharides. The glycolipid (C), for example, was synthesized by reacting mannose $\left(5.4 \mathrm{~g}, 3.0 \times 10^{-2} \mathrm{~mol}\right)$ with L-cysteine $\left(3.6 \mathrm{~g}, 3.0 \times 10^{-2} \mathrm{~mol}\right)$ in water $(25$ $\mathrm{mL})$ containing pyridine $(2.4 \mathrm{~mL})$. The resulting 2-(D-manno-pentahydroxypentyl $)-4$-thiazo- 
lidinecarboxylic acid was blocked with acetyl groups, and was allowed to react with the stoichiometric amount of di-n-dodecylamine in ethyl acetate in the presence of dicyclohexylcarbodiimide.

The intermediate was hydrolysed to give the glycolipid (C) as oil. Yield, 53.64\%; $[\alpha]_{D}^{20}=+$ $11.5^{\circ}$ ( $c=0.5$, methanol). Calcd. for $\mathrm{C}_{33} \mathrm{H}_{67} \mathrm{~N}_{2} \mathrm{O}_{7}$ : C, $52.66 ; \mathrm{H}, 4.93 ; \mathrm{N}, 7.61 \%$. Found : C, $52.21 ; \mathrm{H}, 4.72 ; \mathrm{N}, 7.26 \%$. The glycolipid (F) was obtained by oxidizing (C) $(0.24 \mathrm{~g}, 3.05 \times$ $\left.10^{-4} \mathrm{~mol}\right)$ with $11.5 \mathrm{~N} \mathrm{HNO}_{3}(2.0 \mathrm{~mL})$ : yield, $34.6 \%$.

Reaction substrates such as amylose, cellulose, chitin, and chitosan were prepared by cutting commercially available reagents by means of a Wiley mill into powders (about 60 mesh) without destroying the structure of materials.

Hydrolyses were conducted by mixing $0.01 \mathrm{M}$ solution $(1 \mathrm{~mL})$ of a glycolipid in methanol with a Tris-buffer ( $\mathrm{pH} 7.89,10 \mathrm{~mL})$, adding a carbohydrate $\left(1 \times 10^{-5} \mathrm{~mol}\right.$, calculated as hexose unit), and sonicating the whole mixture, followed by the reaction under magnetic stirring at a fixed temperature. The reaction was monitored quantitatively according to Somogyi-Nelson method.

Hydrolyses of carbohydrates by glycolipids obeyed Michaelis-Menten mechanism in all cases. According HPLC analyses using a Sil $\mathrm{NH}_{2}-5$ column (manufactured by JASCO) (acetonitrile $\left.: \mathrm{H}_{2} \mathrm{O}=65: 35\right)$, reaction products consisted of about $95 \sim 98 \%$ of monosaccharide, about $1 \sim 3 \%$ of disaccharide, and about $0.5 \sim 2 \%$ of oligosaccharides, depending on kinds of carbohydrates. The results are entirely different from that obtained in an acid catalyzed hydrolysis, and indicate that the glycolipid behaves like an exo-type hydrolase.

As shown in Table- 1 , the reaction was very slow at $20^{\circ} \mathrm{C}$, while it proceeded at reasonable rate at $50^{\circ} \mathrm{C}$. Hydrochloric acid in the same concentration $\left(1 \times 10^{-3} \mathrm{M}\right)$ could not hydrolyze any carbohydrate even at the temperature of about $100^{\circ} \mathrm{C}$. This obviously demonstrates the catalytic activity of the glycolipid, though it much depends on the sugar moieties of glycolipids. The glycolipid ( F) containing a carboxylic group was found most active for all kinds of carbohydrates. For example, it exhibited surprising activities of hydrolyzing $53.9 \%$ of chitin and $46.0 \%$ of chito-
Table-1 Hydrolyses of carbohydrates.

\begin{tabular}{|c|c|c|c|c|}
\hline Substrates a) & Catalysts ${ }^{\text {b) }}$ & $\begin{array}{c}\text { Temp. } \\
\left({ }^{\circ} \mathrm{C}\right)\end{array}$ & $\begin{array}{c}\text { Time } \\
(\mathrm{h})\end{array}$ & $\begin{array}{c}\text { Hydrolyzed } \\
(\%)\end{array}$ \\
\hline \multirow[t]{5}{*}{ Amylose } & $\mathrm{C}$ & 50 & 5 & 3.8 \\
\hline & $\mathrm{C}^{\mathrm{d})}$ & 50 & 5 & 95.0 \\
\hline & $\mathrm{D}$ & 50 & 5 & 2.3 \\
\hline & $\mathrm{E}$ & 50 & 5 & 6.3 \\
\hline & $F$ & 50 & 2 & 24.5 \\
\hline \multirow[t]{6}{*}{ Cellulose } & $\mathrm{C}$ & 20 & $14 \mathrm{~d}^{\mathrm{c})}$ & 13.0 \\
\hline & $\mathrm{C}$ & 50 & 9 & 4.3 \\
\hline & $\mathrm{C}^{\mathrm{d})}$ & 50 & 3 & 61.3 \\
\hline & $\mathrm{D}$ & 50 & 3 & 5.3 \\
\hline & $\mathrm{E}$ & 50 & 5 & 7.6 \\
\hline & $\mathrm{F}$ & 50 & 2 & 20.1 \\
\hline \multirow[t]{6}{*}{ Chitin } & $\mathrm{C}$ & 20 & $3 \mathrm{~d}^{\mathrm{c})}$ & 11.8 \\
\hline & $\mathrm{C}$ & 50 & 2 & 5.8 \\
\hline & $\mathrm{C}^{\mathrm{d})}$ & 50 & 2 & 87.2 \\
\hline & $\mathrm{D}$ & 50 & 2 & 18.4 \\
\hline & $\mathrm{E}$ & 50 & 3 & 10.4 \\
\hline & $\mathrm{F}$ & 50 & 3 & 53.9 \\
\hline \multirow[t]{3}{*}{ Chitosan } & $\mathrm{C}$ & 50 & 2 & 3.3 \\
\hline & $\mathrm{D}$ & 50 & 2 & 1.2 \\
\hline & $\mathrm{F}$ & 50 & 3 & 46.0 \\
\hline
\end{tabular}

a) $1 \times 10^{-3} \mathrm{M}$ b) $1 \times 10^{-3} \mathrm{M} \quad$ c) day

d) (C) : phosphatidyl choline $=1: 3$,

Substrates : catalyst $=5: 1$

san for $3 \mathrm{~h}$. In the hydrolyses of chitin, it was found interestedly that the glycolipid (C) hydrolysed only $5.8 \%$ of chitin for $2 \mathrm{~h}$, but its activity was enhanced to hydrolysis of $87.2 \%$ for the same period, when it was diluted with phosphatidyl choline which had no activity at all by itself. This phenomenon seems to relate to the effect of phospholipids on activity of enzymes in a cell.

Table-2 Second order rate constants on hydrolyses ${ }^{\text {a) }}$

\begin{tabular}{c|cccc}
\hline \multirow{2}{*}{ Substrates } & \multicolumn{4}{|c}{$\begin{array}{c}\text { Catalysts } k_{2} \\
\left(\times 10^{-2} \cdot \mathrm{min}^{-1} \cdot \mathrm{M}^{-1}\right)\end{array}$} \\
\cline { 2 - 5 } & $(\mathrm{C})$ & $(\mathrm{D})$ & $(\mathrm{E})$ & $(\mathrm{F})$ \\
\hline Chitin & 3.37 & 198 & 70.4 & 1145 \\
Chitosan & 20.6 & 37.6 & 10.8 & 807 \\
Cellulose & 2.98 & 5.60 & 6.92 & 30.6 \\
Amylose & 2.98 & 1.77 & 8.45 & 34.1 \\
\hline$k_{2}$, cellulose/ & 1.0 & 3.16 & 0.82 & 0.90 \\
$k_{2}$, amylose & \multicolumn{4}{|c|}{} \\
\hline
\end{tabular}

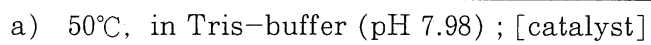
$=1 \times 10^{-3} \mathrm{M}$. 


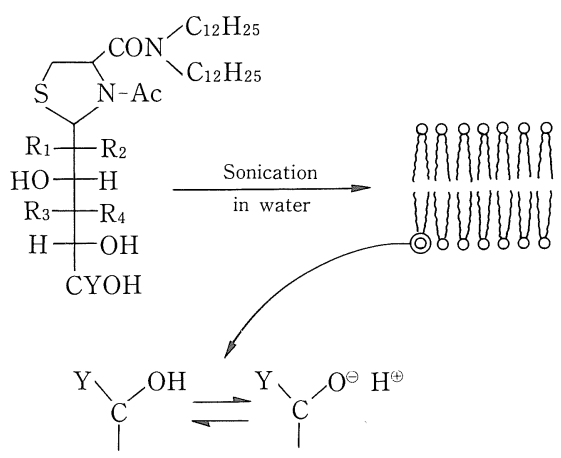

Fig.-1 Postulated action mechanism of glycolipids.

Table-2 shows second-order rate constants of hydrolyses. As mentioned before, suger moieties of glycolipids affected their catalytic activities. The glycolipid ( $F)$, in general, had the highest activity irrespective of substrates. Though the glycolipid well recognized D, L-configurations and kinds of amino acids ${ }^{1,2)}$, it was found also to distinguish 1,4- $\alpha$ and $\beta$-bonds of carbohydrates. The galactose moiety, for example, hydrolyses a $1,4-\beta$-bond at the rate of 3.16 times higher than a $1,4-\alpha$-bond. This is an interesting result, considering that the mannose moiety is preferable in terms of recognition of amino acids ${ }^{2}$.

There remain vague aspects with respect to action mechanisms of enzymes hydrolyzing carbohydrates. To cite one example, however, taka-amylase is said to hydrolyze amylose $e^{4)}$, in which the glutamic acid moiety works as a proton donor to glycoside bonds, while the aspartic acid moiety functions as a stabilizing site on the cleaved cationic intermediate, resulting in the hydrolysis of amylose. Similarly it is postulated that a simple glycolipid used in this study is dissociated ionically, functions as both proton donor and cation stabilizer, and consequently cleaves strong 1,4-bonds of carbohydrates like taka-amylase $\left(\boldsymbol{F i g}_{\circ}-\mathbb{1}\right)$. The details are problems to be investigated in future.

(Received July 21, 1991)

\section{References}

1) a) K. Kawaguch, Y. Ohkatsu, and T. Kusano, Res. Reports of Kogakuin Univ., 80, 96 (1987) ; b) K. Kawaguchi, Y. Miyoshi, S. Shimizu, Y. Ohkatsu, and T. Kusano, Nippon Kagaku Kaishi, 1988, 401 ; c) K. Kawaguchi, Y. Ohkatsu, and T. Kusano, Bull. Chem. Soc. Jpn., 63, 442 (1990).

2) K. Kawaguchi, K. Isobe, Y. Ohkatsu, and T. Kusano, The 1989 International Chemical Congress of Pacific Basin Societies, Hawaii (1989) 04-E 061.

3) Y. Ohkatsu, J. Tsuchiya, K. Kawaguchi, and T. Kusano, International Symposium on Molecular Recognition and Inclusion, Berlim (1990) L 31.

4) M. Onishi, Y. Sakano, and H. Taniguchi, Amylase, 1986, 273. 